and printed 3-dimensional models for volumetric measurement of alveolar clefts before grafting with alveolar bone compared with a validated algorithm: a preliminary investigation", British Journal of Oral and Maxillofacial Surgery, Vol 55, p31 - 36.

7. Hynes P. J., Earley M. J. (2003), "Assessment of secondary alveolar bone graftingusing a modification of the Bergland grading system", The British Association of Plastic Surgeons, Vol 562003, p630 - 636 .

8. R. E. C. M. Mooren, (2007), "The effect of platelet - rich plasma on early and late bone healing: an experimental study in goats", Int. J. Oral Maxillofac. Surg. 2007, Vol36, p626-631.

\title{
KHẢO SÁT TÁC ĐộNG CỦA TENOFOVIR DISOPROXIL FUMARATE LÊN CHỨC NĂNG THẬN Ở BỆNH NHÂN VIÊM GAN VI RÚT B MẠN
}

\section{TÓM TẮT}

Mục tiêu: Khảo sát tác động của tenofovir disoproxil fumarate (TDF) lên chức năng thận ở bệnh nhân viêm gan vi rút $B$ mạn. Đối tượng và phướng pháp: Nghiên cứu cắt ngang mô tả tiến hành trên 60 bệnh nhân viêm gan $B$ mạn điều trị ngoại trú với TDF tại Bệnh viện Đại Học Y Dược TP HCM từ tháng 05/2017 đến tháng 10/2020. Kết quả: Tuổi trung bình trong nghiên cứu là $42,10 \pm 13,30$; Tỷ lệ nam giới 39/60 (65,0\%). Mức creatinine trung bình đã̃ tăng đáng kể ở tuần thứ 24 và $48(p<0,01)$. Tương tự, độ lọc cầu thận ước tính (estimated Glomerular Filtration Rate - eGFR) giảm có ý nghĩa ở tuần thứ 24 và 48 ( $\mathrm{p}$ $<0,05)$. Kết luận: Kết quả nghiên cứu cho thây chức năng thân giảm so với ban đầu ở bênh nhân viêm gan vi rút $\mathrm{B}$ mạn điều trị TDF, cho thấy chức năng thận cần được theo dõi thường xuyên ở những bệnh nhẩn đang điều trị với TDF. mạn.

Tư khóa: TDF, chức năng thận, viêm gan vi rút B

\section{SUMMARY}

\section{EFFECT OF TENOFOVIR DISOPROXIL} FUMARATE ON RENAL FUNCTION IN PATIENTS WITH CHRONIC HEPATITIS B

Objective: To evaluate the effect of tenofovir disoproxil fumarate (TDF) on renal function in patients with chronic hepatitis B. Methods: A cross-sectional study was conducted on 60 patients with chronic hepatitis B at University Medical Center HCMC from May 2017 to October 2020. Results: The mean age of patients was $42.10 \pm 13.30 ; 39 / 60(65 \%)$ of patients were male. The mean creatinine level significantly increased at $24^{\text {th }}$ and $48^{\text {th }}$ week of treatment ( $p<0.01)$, while eGFR level significantly decreased at $24^{\text {th }}$ and $48^{\text {th }}$ week $(p<0.05)$. Conclusion: Renal function was decreased relative to baseline in chronic hepatitis $B$ patients receiving TDF

${ }^{1}$ Đại học Y Dược Thành phố Hồ Chí Minh ²Bệnh viện Chợ Rẫy, Thành phố Hồ Chí Minh

Chiu trách nhiệm chính: Võ Duy Thông

Email: duythong@ump.edu.vn

Ngày nhận bài: 26.10.2020

Ngày phản biên khoa họ: 27.11.2020

Ngày duyệt bài: 2.12.2020

\section{Võ Duy Thông ${ }^{1,2}$, Võ Ngọc Diễm ${ }^{1}$}

therapy, which indicates that the renal function should be monitored regularly in patients undergoing treatment with TDF.

Key words: TDF, renal function, chronic hepatitis B.

\section{I. ĐĂT VẤN ĐỀ}

Nhiễm viêm gan vi rút $B$ (Hepatitis $B$ virus $\mathrm{HBV}$ ) là một vấn đề sức khỏe toàn cầu. Trên toàn thế giới, ước tính có khoảng 240 triêu người bị nhiễm viêm gan vi rút $B$ mạn, đặc biêt ở các nước có thu nhập thấp và trung bình. Các biến chứng chính của viêm gan vi rút $\mathrm{B}$ mạn là xơ gan và ung thư biểu mô tế bào gan (HCC). Khoảng $20 \%$ đến $30 \%$ trong số những người bị viêm gan vi rút $\mathrm{B}$ man sẽ phát triển các biến chứng này, và ước tính khoảng 650000 người sẽ tử vòng hàng năm [1]. Những tiến bô trong điều trị kháng ví rút đã cải thiện đáng kể tiên lượng nhiễm HBV. Tenofovir disoproxil fumarate (TDF) là một tiền chất sinh khả dụng của tenofovir, là một nucleotide manh ức chế quá trình phiên mã ngược HBV [1]. TDF được thải trừ bởi quá trình thanh thải ở thận, phần lớn qua lọc cầu thận; $20 \%-30 \%$ được vận chuyển tích cực vào tế bào ống lượn gần. Độc tính trên thận do TDF chủ yếu dẫn đến tổn thương ống thận gần [2]. Vì vậy, chúng tôi thực hiện đề tài này nhằm khảo sát tác động của TDF lển chức năng thận ở bệnh nhân viêm gan vi rút $B$ mạn.

\section{II. ĐỐI TƯỢNG VÀ PHƯƠNG PHÁP NGHIÊN CỨU}

Thiết kế nghiên cứu: Nghiên cứu cắt ngang mô tả trên hồ sơ bệnh án của bệnh nhân viêm gan vi rút $B$ mạn điều trị TDF.

\section{Đối tượng nghiên cứu}

Tiêu chuẩn chơn bệnh nhân nghiên cứu: 60 bệnh nhân được chẩn đoán xác định viêm gan vì rút $B$ mạn điều trị ngoại trú với TDF tại Bệnh viện Đại Học Y Dược TP. Hồ Chí Minh từ 05/2017 đển $10 / 2020$

- Tiêu chuấn loại trứ: Đồng nhiễm viêm gan vi rút $\mathrm{C}, \mathrm{HIV}$; Có bệnh gan cấp tính do HAV, 
bệnh lý gan cấp do rượu, do thuốc hay nguyên nhân khác.

Cỡ mẫu: Tất cả bệnh nhân thỏa tiêu chuẩn chọn mẫu và không có tiêu chuẩn loại trừ.

Các bước tiến hành và phân tích số liệu. Chúng tôi tiến hành thu thập số liệu từ hồ sơ bệnh án ngoại trú tại phòng khám Viêm Gan Bệnh viện Đại học Y Dược TP Hồ Chí Minh. Hồi cứu tất cả các bệnh nhân đến khám tại phòng khám Viêm gan từ tháng 05/2017 đến 10/2020, thỏa tiêu chuẩn chọn bệnh, không vi phạm tiêu chuẩn loại trừ. Ghi nhận các thông tin bằng bảng thu thâp số liệu.

Phân tích số liệu bằng phần mềm Stata 14.0. Các mối liên hệ được kiểm định bằng phép kiểm t với $p<0,05$ được xem là có ý nghĩa thống kê.

Vấn đề y đức: Nghiên cứu được Hội đồng nghiên cứu Khoa học của Đại học Y Dược TP. Hồ Chí Minh thông qua.

\section{KẾT QUẢ NGHIÊN CứU}

Đặc điểm dân số nghiên cứu. Từ tháng 05/2017 đến tháng 10/2020 chúng tôi thu nhận được 60 bệnh nhân đủ tiêu chuẩn và đưa vào nghiên cứu với tuổi trung bình là 42,10 $\pm 13,30$. Có 65,0 \% (39/60) bệnh nhân nam. Trung bình creatinine nền và eGFR lần lượt là $0,87 \pm 0,19$ $\mathrm{mg} / \mathrm{dl} ; 91,50 \pm 17,90 \mathrm{ml} / \mathrm{ph} / 1.73 \mathrm{~m}^{2}$ da. Phân bố về các đặc điểm của nhóm dân số nghiên cứu được trình bày ở Bảng 1.

Bảng 1. Đặc điểm dân số nghiên cứu

\begin{tabular}{|c|c|}
\hline Đặc điếm & Tống $(\mathbf{n}=\mathbf{6 0})$ \\
\hline Tuối (năm) & $42,10 \pm 13,30$ \\
\hline Giới tính [n (\%)] & \\
Nam & $39(65,0 \%)$ \\
Nữ & $21(35,0 \%)$ \\
\hline Creatinine (mg/dl) & $0,87 \pm 0,19$ \\
\hline eGFR (ml/ph/1,73m² & $91,50 \pm 17,90$ \\
\hline da) & $77,95 \pm 104,69$ \\
\hline AST (UI/L) & $120,95 \pm 215,97$ \\
\hline ALT (UI/L)
\end{tabular}

TB \pm ĐLC: Trung bình \pm Độ lệch chuấn hoặc tần suất (\%)

Sự thay đổi creatinine và eGFR. Sự thay đổi trung bình của creatinine và eGFR được tính toán sau 12, 24, 48 tuần điều trị với TDF (Bảng 2 và Hình 2).

Qua khảo sát chúng tôi nhận thấy rằng, có sự gia tăng đáng kể mức creatinine trung bình ở tuần thứ 24 và $48(p<0.05)$. Tương tự, eGFR đã giảm có ý nghĩa ở thời điểm 24, 48 tuần $(p<0.05)$.

Bảng 2. Sự thay đổi creatinine, eGFR trong điều trị TDF

\begin{tabular}{|c|c|c|c|}
\hline Tuân & $\mathbf{n}$ & $\begin{array}{c}\text { Trung bình } \mathbf{\pm} \\
\text { SD }\end{array}$ & $\begin{array}{c}\text { Giá trị pr } \\
\text { so sánh } \\
\text { với tuân 0 }\end{array}$ \\
\hline \multicolumn{4}{|c|}{ Creatinine } \\
\hline 0 & 47 & $0,87 \pm 0,19$ & \\
\hline 12 & 32 & $0,89 \pm 0,17$ & $\mathrm{p}=0,05$ \\
\hline 24 & 36 & $0,92 \pm 0,16$ & $\mathbf{p}=\mathbf{0 , 0 2}$ \\
\hline 48 & 40 & $0,93 \pm 0,18$ & $\mathbf{p}=\mathbf{0 , 0 4}$ \\
\hline \multicolumn{4}{|c|}{ eGFR } \\
\hline 0 & 47 & $91,50 \pm 17,90$ & $\mathrm{p}=0,08$ \\
\hline 12 & 32 & $88,30 \pm 16,10$ & $\mathbf{p}=\mathbf{0 , 0 4}$ \\
\hline 24 & 36 & $85,30 \pm 14,30$ & $\mathbf{p}=\mathbf{0 , 0 4}$ \\
\hline 48 & 30 & $84,90 \pm 13,90$ & $\mathbf{p}$ \\
\hline
\end{tabular}

Độ lọc cầu thân ước tính

Trung bình \pm ĐLC: Trung bình \pm Độ lệch chuẩn

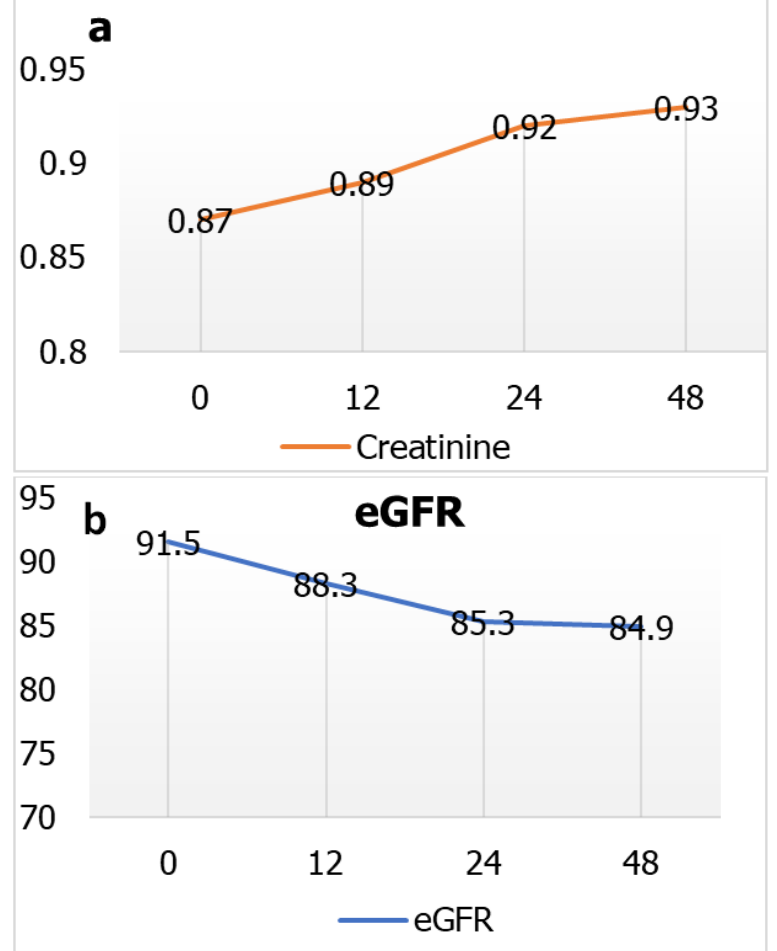

Hình 2: (a) Sự thay đổi creatinine (b) Sụ thay đổi eGFR

\section{BÀN LUÂN}

TDF là một trong những thuốc kháng vi rút trong điều trị viêm gan $B$ mạn. Tuy nhiên, những tác động của TDF lên chức năng thận vần chưa được sáng tỏ. Koklu $S$ và cộng sự đã thực hiên nghiên cứu trên 273 bệnh nhân viêm gan $B$ mạn điều trị TDF > 24 tuần, mức eGFR ở 24 tháng thấp hơn so với lúc ban đầu $(-3,99$ $\mathrm{mL} /$ phút/1,73m2) [5]. Một nghiên cứu khác của 
Pradat $P$ và cộng sự trên 50 bệnh nhân viêm gan $\mathrm{B}$ mạn điều trị TDF > 48 tuần nhận thấy rằng mức eGFR trung bình ở cuối theo dõi thấp hơn lúc ban đầu ( $-6 \mathrm{~mL} / \mathrm{phút} / 1,73 \mathrm{~m} 2)$ [4].

Trong nghiên cứu của Woo Jin Jung và cộng sự (2018), ở 110 bệnh nhân điều trị TDF kéo dài $>48$ tuần cũng ghi nhận mức creatinine đã tăng đáng kể ở 12, 24, 48, 72 và 96 tuần, trong khi mức eGFR cũng giảm có ý nghĩa tại 5 thời điểm này $(p<0,001)[7]$.

Nghiên cứu của chúng tôi cũng đã nhận thây sự gia tăng đáng kể mức creatinine trung bình ở thời điểm 24 và 48 tuần, đồng thời mức eGFR trung bình giảm có ý nghĩa tại thời điểm 24 tuần và 48 tuần so với mức ban đẩu với $\mathrm{p}<0.05$. Tuy nhiên nghiên cứu của chúng tôi còn hạn chế do là nghiên cứu hồi cứu, cỡ mẫu nhỏ, thời gian theo dõi mẫu ngắn.

Cũng theo hướng dẫn của Hiêp hội Nghiên cứu Gan châu Âu (EASL), tất cả bệnh nhân bắt đâu TDF nên được xét nghiệm nồng độ creatinine huyết thanh trước khi điêu trị [3]. Theo Hiệp hội Nghiên cứu bệnh gan Châu Á-Thái Bình Dương (APASL) 2016, do tiềm năng độc tính trên thận của TDF, nồng độ creatinine huyết thanh nên được theo dõi 3 tháng một lần trong khi điều trị bằng TDF [6].

\section{KẾT LUẬN}

Kết quả nghiên cứu chỉ ra chức năng thận giảm so với ban đầu ở bệnh nhân viêm gan $B$ mạn điều trị TDF, cho thấy chức năng thận cần được theo dõi thường xuyên ở những bệnh nhân đang điều trị với TDF.

\section{TÀI LIÊU THAM KHẢO}

1. Gallant JE, Deresinski S. Tenofovir disoproxil fumarate. Clin Infect Dis. 2013;37(7):944-950.

2. Goicoechea M, Liu S, Best B, Sun $S$, et al. Greater tenofovir-associated renal function decline with protease inhibitor-based versus nonnucleoside reverse-transcriptase inhibitor-based therapy. J Infect Dis. 2008;197:102-108.

3. EASL clinical practice guidelines. Management of chronic hepatitis B virus infection. J Hepatol. 2012;57(1):67-185.

4. Pradat $\mathbf{P}$, Le Pogam MA, Okon JB, Trolliet $\mathbf{P}$, et al. Evolution of glomerular filtration rate in HIVinfected, HIV-HBV-coinfected and HBV-infected patients receiving tenofovir disoproxil fumarate. J Viral Hepat. 2013; 20 (9): 650-657.

5. Koklu S, Gulsen $M T$, Tuna $Y$, Koklu $H$, et al. Differences in nephrotoxicity risk and renal effects among anti-viral therapies against hepatitis $\mathrm{B}$. Aliment Pharmacol Ther. 2015; 41 (3): 310-319.

6. Sarin SK, Kumar M, Lau GK, Abbas $Z$, et al (2016). Asian-Pacific clinical practice guidelines on the management of hepatitis B: a 2015 update. Hepatol Int. 2016;10 (1): 1-98.

7. Jung WJ, Jang JY, Park WY, Jeong SW, et al. Effect of tenofovir on renal function in patients with chronic hepatitis B. Medicine (Baltimore). 2018; 97(7): e9756.

8. Vittal A, Ghany MG. WHO Guidelines for Prevention, Care and Treatment of Individuals Infected with HBV: A US Perspective. Clin Liver Dis. 2019; 23(3): 417-432.

\title{
XÂY DỰNG QUY TRÌNH SẢN XUẤT MẪU HỒNG CẦU ỨNG DỤNG TRONG NGOẠI KIỂM XÉT NGHIỆM TRUYỀN MÁU
}

\author{
Vũ Quang Huy ${ }^{1,2}$, Huỳnh Thị Diễm Phúc ${ }^{2}$, Nguyễn Khánh Cường ${ }^{2}$
}

\section{TÓM TẮT}

Mục tiêu: Xây dựng quy trình sản xuất mẫu hồng cầu đổng thời đánh giá độ đồng nhất và ổn định của mẫu hồng cầu đáp ứng yểu cầu sử dụng trong ngoại kiểm xét nghiệm truyền máu. Phương pháp: 4 lô mẫu (50 mâu/lô) tương ứng với 4 nhóm máu hệ $A B O$ được sản xuất, 10 mẫu/lô được sử dung để đánh giá độ đồng nhất, 9 mẫu/lô được dùng để đánh giá độ ổn

${ }^{1}$ Đai học y dượ TP. Hồ Chí Minh

${ }^{2}$ Trung tâm Kiểm chuẩn chất lượng xét nghiệm Y học - Đai hoc Y Dước TP. Hồ Chí Minh

Chịu trách nhiệm chính: Vũ Quang Huy

Email: drvuquanghuy@gmail.com

Ngày nhận bài: 28.10 .2020

Ngày phản biên khoa học: 26.11.2020

Ngày duyệt băi: 3.12 .2020 định khi lưu trữ (49 ngày) và 3 mẫu/lô được dùng để đánh giá độ ổn định trong điều kiện vận chuyển (7 ngày). Các thông số kháng nguyên (antigen), số lượng hồng câu (RBC), hematocrit (Hct), hemoglobin (Hb), $\mathrm{Na}^{+}, \mathrm{K}^{+}$, lactate, lactate dehydrogenase (LDH) được dùng để đánh giá và theo dõi chất lượng mẫu. Kết quả: 4 bộ mẫu hồng cầu đã được sản xuất thành công và được đánh giá theo tiêu chuẩn ISO 17043:2010. Các bộ mẫu sản xuất đều đạt độ đồng nhất, ổn định tốt trong 35 ngày và vẫn đảm bảo các tiêu chuẩn thực hành lâm sàng cho đến ngày 49, chất lượng mẫu được đảm bảo trong 7 ngày ở điều kiện vận chuyển. Kết luâan: Xây dựng thành công quy trình sản xuất bộ mẫu hông câu theo tiêu chuấn của ISO 17043:2010. Mẫu hồng câu sản xuất đạt yêu câu chất lượng về độ đồng nhất và ổn định, có thể ứng dụng vào chương trình ngoại kiểm tra chất lượng xét nghiệm truyền máu. 